\title{
The Synergistic AND COMPLEMENTARY EFFECTS OF SuPPLY Chain Justice and Integration Practices On SuPPly Chain Performance: A Conceptual Framework AND RESEARCH Propositions
}

\author{
Muhammad Ziaullah \\ School of Management and Economics, University of Electronic Science and Technology \\ of China and Ghazi University, Dera Ghazi Khan, Pakistan \\ Yi Feng \& Shumaila Naz Akhter \\ School of Management and Economics, University of Electronic Science and Technology \\ of China \\ Accepted: May 15, 2015
}

\begin{abstract}
In recent years, firms have been using their supply chain integration (SCl) as a competitive weapon in the intensive, globalised competitive arena. The contingent perspective in supply chain management maintains that it is necessary to observe the interaction between $\mathrm{SCl}$ practices and supply chain justice. A critical issue to be resolved is whether this fit leads to synergistic and complementary effects on supply chain performance. In order to contribute to this research problem, we analysed supply chain justice instances in order to determine the importance of supply chain justice, as well as highlights complementary role in $\mathrm{SCl}$ and its influences on supply chain performance. A conceptual framework has been developed and five propositions established to verify the contents of a theoretical study. Accordingly, balancing the adoption of $\mathrm{SCl}$ practices and supply chain justice will lead to the generation of greater benefits relative to the effect of both independent driving forces on supply chain performance. Furthermore, the proposed framework has been analysed in order to examine its applicability in the South African context. The study thereby suggests the empirical research guidelines and the paper concludes with a discussion of future research.
\end{abstract}

Key words: supply chain, supply chain justice, supply chain integration, supply chain performance

JEL: M1

\section{$1 \quad$ Introduction}

With the fierce competition in the market companies have been required to participate in SCI. This concept has gained much attention as a result of changing manufacturing and supply chain strategies (Cousins \& Menguc, 2006). SCI, customer-supplier collaboration and partnerships have been highlighted as emerging, substantial and attractive business practices and trends across diverse industries (Shou, Feng, Zheng, Wang \& Yeboah, 2013). The firm's supply chain should be agile, adaptable and aligned to meet the fast-changing requirements of competitive markets (Lee, 2004). What is required is the articulation of a closely integrated relationship between manufacturers and their supply chain partners (Armistead \& Mapes, 1993). SCI refers to the degree to which a manufacturer strategically collaborates with its supply chain partners and collaboratively manages intraorganisational and interorganisational processes. The goal is to achieve effective and efficient flows of products and services, information, capital and decisions, thereby providing maximum value for the customer (Frohlich \& Westbrook, 2001), while, at the same time, making contributions to supply chain performance (Narasimhan \& Kim, 2002) and the firm's operational performance (Frohlich \& Westbrook, 2001).

The literature on supply chain management (SCM) specifies the practices of SCI, such as information sharing, process integration (Yeung, Selen, Zhang \& Huo, 2009) and relationship 
commitment (Benton \& Maloni, 2005; Zhao, Huo, Flynn \& Yeung, 2008). Investigations have shown that different kinds of SCI initiators serve to facilitate and enhance integration processes, for instance information technology (IT) implementation, e-business technologies, and human resource involvement in service roles and socialisation (Armistead \& Mapes, 1993; Cousins \& Menguc, 2006; Li, Yang, Sun \& Sohal, 2009).

For many years researchers have, investigated and explored the theoretical benefits of SCI, but adopting SCI as a common practice has become a great challenge (Frohlich, 2002). Supply chain partners have distinctive objectives that create barriers with regard to SCI. More specifically, members of a supply chain compete for control (Cox, Sanderson \& Watson, 2001), as well as being concerned about chain difficulties and the incurring costs (Krause, 1999). Customers refuse to participate in upward SCI for fear of supply disruptions, and the leaking of confidential information (Corbett, Blackburn \& Van Wassenhove, 1999). Ketchen and Giunipero (2004) suggested that SCM literature often seems to assume that "a rising tide lifts all boats". Thus when the chain is successful all members mutually prosper. Crook and Combs (2007), however, argue that, while strong members reap most of the direct benefits, weak members can often gain by building switching costs with strong members.

The above therefore highlights the critical phenomena and clearly illustrates the important role of justice in SCI. Research on justice in the context of SCI has been incomplete. The justice concept has deep roots in organisational literature and serves as the foundation for all types of social economic exchanges and relationships (Adams, 1965; Lind \& Tyler, 1988). Recently, justice has been examined in the context of supply chain relationships (Griffith, Harvey \& Lusch, 2006; Liu, Huang, Luo \& Zhao, 2012), and it has been recognised that perceptions of justice are of particular importance in long-term relationships, because two parties need to collaborate to some extent in order to leverage each other's capabilities and resources to achieve mutual goals. A failure to develop perceptions of justice may result in harm to, or termination of, the relationship (Liu et al., 2012).

Importantly, justice has played a critical role in improving supply chain relationship performance and each category of justice has unique contributions to make to the significance of supply chain relationships (Liu et al., 2012; Narasimhan, Narayanan \& Srinivasan, 2013). The literature on justice (both at the individual and organisational levels) has mainly examined three dimensions namely procedural, distributive and interactional justice (Colquitt, Conlon, Wesson, Porter \& Ng, 2001; Luo, 2007). "Supply chain procedural justice" refers to supply chain partners' perceptions of the fairness of formal procedures in the context of SCI; "supply chain distributive justice" refers to supply chain partners' perceptions of the fairness of the distribution outcome in this context of SCI; and "supply chain interactional justice" is the extent to which supply chain partners' consider that there is fair treatment in respect of interpersonal and informational aspects in the context of SCI. Problems related to interactional justice may occur when supply chain partners believe that they are not being treated with respect and dignity by other members of the supply chain.

Griffith et al. (2006) found that perceived procedural and distributive justice have improved long-term orientation and relational behaviour, have reduced conflict, and have increased satisfaction. Researchers studying SCI from a practical point of view have examined SCI practices such as information sharing, process integration and relationship commitment and found that these practices make significant contributions to a firm's supply chain and operational and business performance. SCI practices and characteristics have strong theoretical roots, but, in practice anecdotal evidence organizations is scare. Beugré and Acar (2008) construe justice as a mechanism that enhances relationships between partners and creates a fundamental bond in inter organisational relationships.

To the best of our knowledge, there is no prior research on SCM, including the research by Liu et al. (2012), that has examined the direct and complementary effect of SCI practices and justice on supply chain performance (SCP). The present study is therefore a step towards filling this gap. 
Firstly, the study demonstrates the direct effects of SCI practices and justice on firms' SCP. Secondly, it considers the complementarities between supply chain justice and integration practices as being crucial from the point of view of their influence on SCP. Hence, we argue that firms have a greater likelihood of achieving SCP if they have both strong SCI practices and a strong perception of justice with regard to SCI.

The purpose of this paper is thus to develop a conceptual framework and a series of propositions based on a literature review and an examination of practical situations in order to describe the main effects of SCI practices and justice dimensions on SCP. This research also attempts to indicate how SCI practices and justice dimensions may interact in impacting SCP. A general assertion of this paper is that firms have a greater likelihood of achieving SCP if they have a strong conscience in implementing of SCI practices and justice dimensions. The two constructs are expected to have independent, and often complementary and synergistic effects, on SCP.

The remainder of this paper is organised as follows. Section 2 presents the conceptual background. In Section 3, the relationship between SCI practices and SCP is set out. The relationship between supply chain justice and SCP is presented in Section 4. Then, in Section 5, we demonstrate the synergistic and complementary effects of SCI practices and supply chain justice on firms' SCP. Section 6 discusses the implications of research in the context of South African firms. Finally, Section 7 describes the guidelines developed for empirical research, and in Section 8 , conclusions are reached and future research directions are given.

\section{Conceptual background}

\subsection{Complementarities and main effects}

Edgeworth (1881) originally introduced the concept "complementarities", describing the activities concerned as complementary if doing (more of) any one of them increases the returns of doing (more of) the others. Ennen and Richter (2010) proposed that some activities and practices of firms are mutually complementary and tend to be adopted together, with each enhancing the contribution of the other.

A complementary interaction of a firm's practices and resources could create super-additive synergies. Hence, the inter-firm design variables and practices contribute maximally to the overall success of integration (Barua \& Whinston, 1998). Ranganathan, Teo and Dhaliwal (2011) suggest that complementary or interacting of capabilities and practices are the core motivations for supply chain relationships, as they help to create value that cannot be generated independently.

Many researchers have investigated the indirect effect of supply chain integration practices (Yang \& Burns, 2003; Schloetzer, 2012; Wiengarten, Humphreys, Cao, Fynes, \& McKittrick, 2010) and justice (Liu et al., 2012) on performance by using various types of mediating variables. For instance, Liu et al. (2012) examined the effects of justice aspects on dyadic relationship performance through a mediating variable of mutual coupling behaviours. Our point of departure is the shared concern of previous studies for supply chain integration practices and justice dimensions. However, unlike Liu et al. (2012), we use the complementary effect and argue that neither SCI practices nor justice components by themselves are sufficient to sustain SCI and achieve superior SCP. Instead, these phenomena need to operate in tandem in order to achieve the desired outcomes of SCI.

Therefore, this study is concerned with conceptually proposing the direct and complementary effects of SCI practices and justice on firms' supply chain performance. Thus, we argue that complementarities between supply chain justice and integration practices will be greater than the sum of their parts because of the synergistic effects of bundling both together. Further, the complementary association of SCI practices and justice components will develop and sustain the relationships, which, in turn, will culminate in SCP.

The complementary concept offers a useful perspective for understanding the complex relationships between supply chain justice and integration practice. In our study, complementarity 
indicates a condition of increasing returns in which adopting (doing more of) integration practices have a greater payoff when simultaneously adopting (doing more) a complementary activity (e.g. ensuring high levels of justice perception) in SCI.

\subsection{Conceptual framework}

This study considers three dimensions of supply chain justice namely procedural, distributive and interactional dimensions, and three aspects of SCI practices, like information sharing, process integration and relationship commitment in the context of SCP. As the literature suggests, the competitive priorities (i.e. cost, quality, speed and flexibility) are critical in the measurement of SCP (Hult, Ketchen, Cavusgil \& Calantone, 2006). We intend to apply the concept of organisational justice in inter-firm analysis of the supply chain. We use the term "inter-firm supply chain justice" to refer to supply chain partners' perceptions of the fairness of one another's actions in supply chain relationships. Moreover, we use SCM literature and practical instances to develop the conceptual model and research propositions. Hence, we propose a conceptual framework for describing their interrelationships in Figure 1. The model indicates that supply chain justice dimensions and SCI practices may each directly affect SCP, and that they may also interact synergistically in their impact on SCP.

Figure 1

Conceptual framework

\section{Supply chain integration practices}

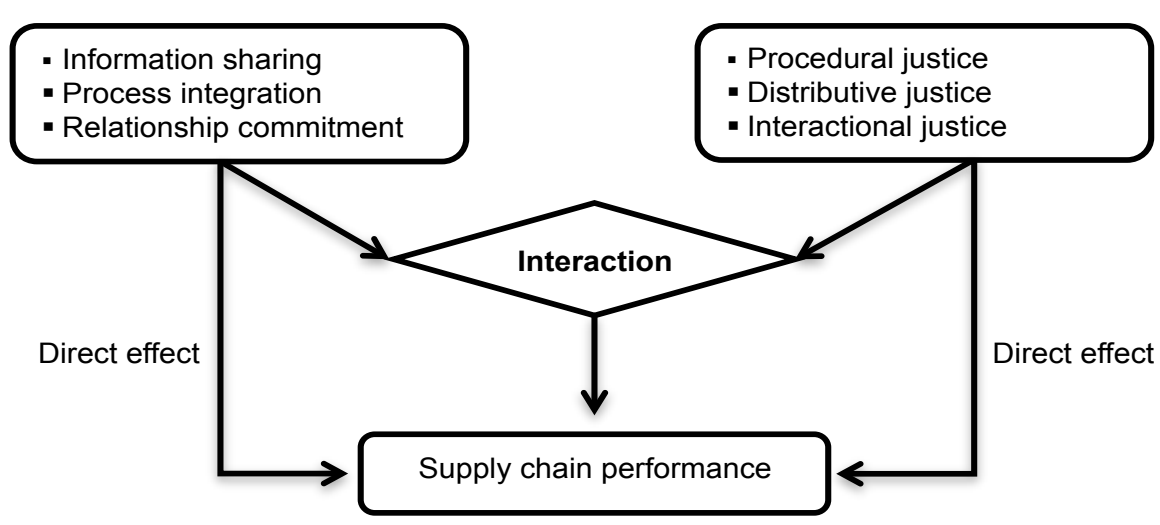

\section{The relationship between SCI practices and supply chain performance (SCP)}

Yeung et al. (2009) consider SCI practices as information sharing and process integration, while other researchers have highlighted the importance of another practice, namely relationship commitment (Benton \& Maloni, 2005; Zhao et al., 2008). "Information sharing" refers to the extent to which critical and proprietary information is communicated to supply chain partners (Mohr \& Spekman, 1994). It is key to establishing a seamless supply chain to ensure undistorted and real-time market data access at every node within the supply chain (Towill, 1997). Information sharing is an essential requirement (Sheu, Yen \& Chae, 2006), is the foundation of SCI (Lee \& Whang, 2001), and improves firms' overall performance (Yang \& Burns, 2003).

"Process integration" refers to the extent to which a firm can structure its operational processes, as well as the sharing of resources, rewards and risks across organizations, into consensus agreements in order to achieve competitiveness (Yeung et al., 2009). It integrates the processes of 
different functions within a company or different firms within a supply chain (Kanda \& Deshmukh, 2008) and also refers to the extent to which partners standardise and synchronise inter-firm processes (Zhou \& Benton, 2007). Process integration has contributed to reduced production costs through economies of scale, reduced lead time, inventory savings, and improved asset utilisation (Maloni \& Benton, 2000). It has also enriched firm-effectiveness and innovation related capabilities (Frohlich \& Westbrook, 2001). Investigations have shown that overall process integration has positively influenced sales growth, sales productivity and partnership profitability, has facilitated mutual value creation and has generally favourable financial implications for supply chain partners (Schloetzer, 2012).

"Relationship commitment" may be defined as a situation where an exchange partner believes that an ongoing relationship with another is so important as to warrant maximum effort at maintaining the relationship, that is, the committed party considers the relationship to be worth working on so as to ensure that it endures indefinitely (Morgan \& Hunt, 1994). Such commitment also results in mutual gains for suppliers and buyers in a supply chain relationship (Jaros, Jermier, Koehler \& Sincich, 1993). Such a stable and long-lasting relationship has become critical in realizing long-term benefits for supply chain partners (Anderson \&Weitz, 1992; Moore, 1998). Moreover, it has been proven that relationship commitment to the customer is positively related to customer and supplier integration (Zhao et al., 2008). Most researchers who have studied SCI from the perspectives of suppliers and customers (e.g. Kim, 2006) refer to this aspect as external integration (Danese, Romano, \& Formentini, 2013), which is directly related to operational performance (Wiengarten et al., 2010).Therefore, we formulate the following proposition.

Proposition 1: In the context of supply chain integration (SCI), there is a positive relationship between SCI practices (information sharing, process integration, and relationship commitment) and supply chain performance (SCP).

\section{The relationship between supply chain justice dimensions and supply chain performance (SCP)}

The first justice dimension is procedural and is derived from the idea of instrumentality (Luo, 2007). It refers to the fairness of decision making procedures (Phillips, Douthitt \& Hyland, 2001) and is based on the processes or procedures by means of which resources are allocated and decisions are made (Hendrix, Robbins, Miller \& Summers, 1998).

"Distributive justice" is the second dimension of justice and is derived from the idea of equity. Equity theory suggests that rewards should be distributed equitably among the transacting parties in relation to their contribution (Adams, 1965). Such theory is integral to developing, sustaining and improve the stable and cooperative interorganisational relationships (Ring \& Van de Ven, 1994; Scheer, Kumar \& Steenkamp, 2003). Luo (2007) defined distributive justice as the extent to which interparty sharing of the rewards of cooperation is fair in view of each party's contribution, commitment, and assumption of responsibility and stated examples of outcomes such as knowledge acquisition, profit, reputation enhancement, and dividends. Distributive justice means that firms will always receive economic rewards proportionate to their input contributions in the relationship (Kumar, Scheer \& Steenkamp, 1995).

"Interactional justice" is the third dimension of justice and is extracted from the idea of social exchange. It refers to the extent to which interpersonal treatment and information exchange between boundary spanners representing each party, is fair. It complies with social sensitivity to partners and includes courtesy, openness, feedback, honesty, mutual understanding, and demonstrations of great respect for each other's social norms in the sphere of interpersonal treatment (Luo, 2007). "Interactional justice" also refers to the extent to which people receive quality interpersonal treatment during the implementation of procedures. Four rules or criteria relating to interactional justice are explored, namely truthfulness, justification, respect and property. In the supply chain context, "interactional justice" can also be defined as the degree of openness shown by the transacting parties in communicating relevant information and in 
managing conflict (Narasimhan et al., 2013). It is focused on aspects of fairness related to interpersonal issues and information exchange in social context (Colquitt, 2001; Ariño \& Ring, 2010), although it relates to the openness of communication among supply chain partners (Luo, 2007). Openness relates to greater sensitivity in managing conflict and disparities ( $\mathrm{Lu}, 2006)$.

Narasimhan et al. (2013) found that justice is important for improving supply chain relationship performance and that each category of justice has unique contributions and an important part to play in supply chain relationships. Griffith et al. (2006) stated that perceived procedural and distributive justice have improved long-term orientation and relational behaviour, have reduced conflict and have increased satisfaction. Liu et al. (2012) reported that all justice categories have significant influence on dyadic relationship performance in the context of the supply chain. It is suggested that mutually perceived justice by partners contributes to enhanced performance owing to the coupling link of knowledge sharing, relational investment and continuous commitment. Justice is important for accomplishing superior performance in all economic exchanges (Narasimhan, Nair, Griffith, Arlbjørn \& Bendoly, 2009). Therefore, we formulate the following proposition.

Proposition 2: In the context of SCI, there is a positive relationship between supply chain justice dimensions (procedural, distributive and interactional) and supply chain performance (SCP).

\section{$5 \quad$ The symergistic and complementary role of supply chain justice together with SCI practices in supply chain performance (SCP)}

Luo (2007) defined procedural justice in the context of strategic alliances in China as "the extent to which the strategic decision making process and procedures that impact each party's gains and interests are impartial and fair as perceived by the boundary spanners representing each party in an alliance". The intention is to produce a sense of procedural justice as a partner assesses the fairness of the formal procedures governing the creation and functioning of the collaborative arrangement. However, the absence of these procedures may result in perceptions of procedural injustice. In the absence of procedural justice, partners may exert pressure on the other party to follow existing procedures or may threaten to leave the strategic arrangement (Beugré \& Acar, 2008). Investigations have shown that a party may perceive low procedural justice as tending to deliver low commitment to the joint venture (Johnson, Korsgaard \& Sapienza, 2002).

Similarly, Luo (2005) found that alliance profitability was higher when both parties perceived higher rather than lower procedural justice. Cropanzano, Bowen and Gilliland (2007) stated that process actually encourages an individual's willingness to serve in the greater interest of a relationship. This phenomenon is true in the context of the organisation (Narasimhan et al., 2013). Hald and Ellegaard (2011), in their case study on the supplier-evaluation process and consequent price quotes by suppliers found that, where suppliers perceived a process to be unfair, they quoted a higher price in subsequent interactions. Narasimhan et al. (2013) noted the comments of a senior procurement executive in a leading oil-producing firm about supply chain procedural justice. The executive stated that, in the past, they had negotiated a framework agreement with a supplier about market commercial terms. The supplier was then bound to do the initial work (which was fairly extensive) at cost, based on the expectations that, if the supplier did the work well, such supplier would be rewarded for the next phase of the project. However, the inconsistencies found during implementation of the agreement had led to frustration that was not conducive to a sustainable relationship. As a result, the firm had introduced some changes to ensure fair compensation for work done that had led to a stronger relationship of openness and trust. Liu et al. (2012) pointed out that some long-term suppliers such as COFCO (the largest supplier of diversified agricultural products in China's food industry) and Master Kong (a food and beverage company) had claimed that the annual contract-negotiation process with Carrefour had been extremely difficult and that subsequent execution of consent terms was often not guaranteed. Similarly, the French automaker, Peugeot terminated its venture relationship and participation with its partner in China, the reason being that it had realised that local partners were procedurally undercutting its managerial 
autonomy and participative power in the alliance compared with its contribution. This decision was, therefore, taken in the context of perceived procedural injustice (Harwit, 1997). Sometimes, even procedural injustice on the supplier's part will be regarded as injustice within the company. Nike's Asian subcontractors, for instance, have compelled their employees to work long hours (about 10.5 hours per day) for six consecutive days for the equivalent of only $\$ 10$. Though Nike was not directly involved in these violations of justice, such violations actually tarnished the reputation of Nike. It can thus be argued that Nike engaged in procedural injustice as a result of its suppliers failing to adhere to proper and fair work procedures (Beugré \& Acar, 2008; Beugr, 2007). Turning to process integration, this may be defined as the degree of overall coordination of business processes and activities between supply chain partners. It involves effective division of tasks across units and consequent coordination in order to execute the task within the firm or between partners (Van de Ven, Delbecq \& Koenig, 1976). Where both buyer and supplier perceive high levels of procedural justice, they will recognise that their benefits are protected through policies and will accordingly be willing to invest in the relationship. For instance, Wal-Mart China and its suppliers mutually perceive a high level of procedural justice, which signifies consistency in exchange processes and the likelihood of outcomes (Liu et al., 2012). Kumar et al. (1995), indicating that trade channel members' perception of their partner's procedural justice has a strong effect on their willingness to invest in the relationship. Similarly, procedural justice is also essential for the purpose of information sharing (Liu, Liu, Kwok-Kee \& Hua, 2014).

From the aforementioned practical examples, it is clear that supply chain procedural justice between members of the supply chain has become integral to the success of SCI. Thus, even though there have been situations where SCI practices have prevailed, the relationship between partners has been terminated on account of procedural injustice. Procedural justice and SCI practices may therefore be synergistic and complementary in their impact on SCP. The model thus indicates that procedural justice and SCI practices could interact in impacting SCP. Thus we formulate the following propositions.

Proposition 3a: Complementarities between supply chain procedural justice and the integration practice of information sharing are necessary for supply chain integration (SCI), and, therefore, for supply chain performance (SCP) improvement.

Proposition 3b: Complementarities between supply chain procedural justice and the practice of process integration are necessary for supply chain integration (SCI), and, therefore, for supply chain performance (SCP) improvement.

Proposition 3c: Complementarities between supply chain procedural justice and the integration practice of relationship commitment are necessary for supply chain integration (SCI), and, therefore, for supply chain performance (SCP) improvement.

It should be pointed out that partners strive to achieve the common objectives of their multi-partner alliances, even though they may differ with respect to their individual interests and may compete for their share of alliance benefits (Lavie, Lechner \& Singh, 2007). It is proposed that a firm invests in a relationship with the expectation of receiving some rewards in terms of outcomes such as profit, access to technology, or access to new markets. Each partner desires to compare their input output ratio with that of the other partner in the relationship. A sense of fairness arises as partner actions meet expectations. However, where such actions fall short of expectations, feelings of unfairness are experienced (Beugré \& Acar, 2008). According to Barden Steensma and Lyles (2005), partners in a cooperative relationship will expect the outcomes of the cooperative arrangement to be distributed in proportion to the partner contributions. Violations of this principle may lead to mistrust, conflict, dysfunction, self-serving behaviour, and, ultimately, the dissolution of the relationship (Scheer et al., 2003; Ring \& Van de Ven, 1994). Importantly, equity is essential to the development of stable and productive inter-firm relationships (Barden et al., 2005). It is suggested that, where a partner believes that positive returns are not occurring or that they are not being fairly rewarded relation to their contributions, they may find ways to divest themselves of the unprofitable venture (Beugré \& Acar, 2008). 
In this regard, Jusko (2011) quotes the words of the chief executive officer (CEO) of Talan Products, a Cleveland based metal stamping company: "If a relationship is cannibalistic, some day dinner is going to run out. You're going to eat the [company] up". Narasimhan et al. (2013) quote the words of a senior procurement executive of an offshore oil-drilling-equipment firm: "Risk and reward sharing have a visible financial impact" on supply chain relationships. Perhaps it could be stated that distributive injustice can lead to opportunistic behaviours. Beugré and Acar (2008) note that, in case of a United States based company which subcontracts its operations to a firm located in Asia, the subcontractor has experienced distributive justice owing to the fact that contracting company has bought its output at a reasonable price. Liu et al. (2012) state that, in the case of Carrefour, suppliers have in fact complained about their lean profits, in addition to slotting fees and promotion fees. It is maintained that Carrefour, has contrived a wide range of reasons to levy surcharges on suppliers, that is, anniversary fees, store-grand-opening fees and holidaycelebration fees. In view of this, suppliers have chosen to terminate their relationship with Carrefour, citing severe injustice issues with respect to the supply chain. Morgan and Hunt (1994) state that "relationship commitment" can be seen as the willingness of a party to invest financial, physical or relationship-based resources in a relationship. In the context of the supply chain, partners require the development and maintenance of a stable, long-lasting mutual relationship (Anderson \& Weitz, 1992). Distributive injustice, it would seem, could lead to opportunistic behaviours where the exchange parties even engage in behaviours that can sabotage the relationship (Narasimhan et al., 2013). However, risk and reward sharing, in particular can be important in mitigating opportunistic behaviour (Eisenhardt, 1989). Distributive justice is also important for supply chain information sharing integration (Liu et al., 2014). In fact SCI practices like information sharing, process integration and relationship commitment have provided a particular mechanism for SCI. However, this does not necessarily a guarantee the success of supply chain relationships among partners in the chain. In particular, it is assumed that, without supply chain distributive justice, SCI would fail even where there is a mechanism of SCI practices existing between participating firms in the supply chain. We would argue that along with SCI practices supply chain distributive justice is essential and complementary, for the better establishment of SCI and will contribute significantly to SCP. The model indicates that distributive justice and SCI practices may interact in their impact on SCP. Thus we formulate the following propositions.

Proposition 4a: Complementarities between supply chain distributive justice and the integration practice of information sharing are necessary for supply chain integration (SCI), and, therefore, for supply chain performance (SCP) improvement.

Proposition 4b: Complementarities between supply chain distributive justice and the practice of process integration are necessary for supply chain integration (SCI), and, therefore, for supply chain performance (SCP) improvement.

Proposition 4c: Complementarities between supply chain distributive justice and the integration practice of relationship commitment are necessary for supply chain integration (SCI), and, therefore, for supply chain performance (SCP) improvement.

Luo (2007) state, in a study of a strategic alliance in China, that local executive felt unjustly treated by their foreign counterparts when they received neither courtesy and respect, nor experienced cultural sensitivity and mutual understanding. It is suggested that interactional injustice will occur when boundary spanners do not share valuable information and do not consider other important inputs. This has been observed, for instance, where a partner does not provide explanations for important decisions. Meanwhile perceptions of improved interactional justice may offer a better social environment in strategic alliances, as well as improved information sharing and personal relationships between boundary spanners representing different parties. In fact, high interactional justice increases solidarity, reduces interparty conflict and improves organisational attachment (Mohr \& Spekman, 1994; Nooteboom, 1996). Narasimhan et al. (2013) note the comments of a senior executive about interactional justice. Such executive, they 
state, maintains that it contributes to openness and trust in a relationship, and that, without openness and trust, the parties are more likely to "fight" for positioning and "gaining the upper hand" as they rationalise the relationship as being competitive in nature where only one can win.

Liu et al. (2012) have found that the personnel of Carrefour suppliers often complain about the way they have been treated by their contacts, and how they have often been kept in the dark as the result of Carrefour changing pricing or the location of their products in the store. Currently, suppliers have chosen to terminate their relationship with Carrefour on account of such relationship causing severe problems in the supply chain. Interactional justice, therefore, can develop greater trust and relationship commitment between transacting parties (Narasimhan et al., 2013), and can also encourage supply chain information sharing integration (Liu et al., 2014).

It is possible that, without information sharing and relationships, the firms might experience difficulties in carrying out the operational activities arising from the relationship, which can then lead to poor performance. Besides the SCI practices, there are various forces that contribute to the establishment of SCI between firms. Similarly, supply chain interactional justice has become quite critical to the successful operation of SCI and to the relationship between firms participating in the supply chain. We argue that supply chain interactional justice has become complementary and integral among SCI practices for establishing SCI and will contribute more significantly to SCP relative to their independent role in SCI. The model indicates that interactional justice and SCI practices may interact in their impact on SCP. Thus we formulate the following propositions.

Proposition 5a: Complementarities between supply chain interactional justice and the integration practice of information sharing are necessary for supply chain integration (SCI), and, therefore, for supply chain performance (SCP) improvement.

Proposition 5b: Complementarities between supply chain interactional justice and the practice of process integration are necessary for supply chain integration (SCI), and, therefore, for supply chain performance (SCP) improvement.

Proposition 5c: Complementarities between supply chain interactional justice and the integration practice of relationship commitment are necessary for supply chain integration (SCI), and, therefore, for supply chain performance (SCP) improvement.

Furthermore, we argue that once both foundational components are in place, potential synergies between SCI practices and supply chain justice as complementary elements can be exploited in order to gain additional performance. The findings from supply chain relationship terminations reflected in the case studies concerned illustrates that firms whose SCI is currently good have, however, not yet paid much attention to supply chain justice between supply chain partners. These organisations are likely to find that implementing SCI practices without reinforcing supply chain justice will not sustain supply chain relationships and bring about significant performance. Such firms should, therefore, focus attention simultaneously on supply chain justice and SCI practices in their supply chain integration.

\section{Discussion and research implications}

We have developed propositions that may serve as guidelines for empirical study. These propositions recognise that SCI practices and justice independently and positively affect SCP. What is also clear from the above is that supply chain injustice has caused the termination of relationships between supply chain partners. For instance, Wal-Mart Canada made a decision to terminate its business relationship with the Lego Group because Lego refused to reduce its prices in the Canadian market to bring them in line with its pricing structure in the United States market. Wal-Mart considered such refusal to be unfair and perceived the Lego Group as being unwilling to share the benefits they were reaping from the appreciation of the Canadian dollar. What had transpired prior to Wal-Mart request to lower prices was that the Canadian government had called on retailers to lower their prices as a result of appreciation of the Canadian dollar, and retailers, in turn, had asked suppliers to lower wholesale prices. The report detailing this sequence of events quoted a Wal-Mart Canada executive as saying that they had told suppliers that they "would not 
tolerate unfair pricing" for their Canadian customers (Georgiades, 2008). A similar relationship termination occurred between the two Chinese firms Gome (a leading Chinese home-appliance retailer) and Gree (a leading air conditioner manufacturer in China) in the summer of 2004. Gree believed that Gome had demanded additional summer-promotion fees which were absolutely unfair and therefore decided to withdraw its entire product range from Gome stores (Asia Info Services, 2004). This situation, led Gree to decide to open its own exclusive stores in order to sell the products. Thus, notwithstanding the circumstances, Gree was able to make good the loss of market share due to the termination of the relationship with Gome (Liu et al., 2012).

Considering the situation in South Africa, it is evident that fair-trade standards have been reworked and implemented. Fair-trade standards specifically, have two interconnected objectives, namely to stabilise supply chain relationships and the social development of communities (Hughes, McEwan, Bek \& Rosenberg, 2014). In South Africa firms have been experiencing supply chain injustice issues. However, economic fairness may nevertheless be questionable owing to unequal market selling power (Ras \& Vermeulen, 2009). For instance Eksteenskuil Agricultural Cooperative (EAC) is the world's first fair-trade-certified raisin producer, with four fair-trade smallholders operating in South Africa. EAC, however, has been facing challenges with regard to ensuring an equitable distribution of benefits (Hughes et al., 2014). The theoretical framework proposed in the paper could, therefore be helpful to South African managers in understanding how justice and SCI practices help firms to improve performance. This study demonstrates that supply chain justice can be regarded as an important stimulus along with integration practices. Therefore, managers should move in the direction of recognising the supply chain justice as well as the viable implementation of integration techniques along with their supply chain partners. This way they can leverage supply chain justice and integration practices in a synergistic way so as to improve performance. The justice perceptions shared by supply chain partners, along with simultaneous implementation of SCI practices can drive better performance. In fact, justice contributes to a fair and just atmosphere with respect to the buyer-supplier relationship, and, in such an atmosphere, firms are more likely to engage in integration practices that lead to superior performance on the part of the firm.

Yet, despite this, there are the chronicled instances of supply chain injustice leading to the termination of supply chain relationships. What our model does acknowledge is that simultaneous complementary implications of SCI practices and justice produce greater benefits for firms relative to their independent consequences. It is strongly suggested, therefore, that, as for as supply chain integration is concerned, participating firms should realise and understand the importance of supply chain justice and its complementary effect on performance. Members of participating firms should consider it a top priority during their transactional interactions with their partners. In order to manage SCI and inter-firm relationships, supply chain members should strive for a convergence of their own justice expectations and those of their partners. This can be done by developing a common code of conduct that clearly spells out the responsibilities and rights of each participating firm.

In fact, since various partners have varying perceptions of, and expectations regarding justice, the development and implementation of a code of conduct are important. Further, perceptions of procedural justice are important for sustainability and the stability of the relationship (Luo, 2005). Accordingly, supply chain partners could therefore design a justice system and ensure its implementation so as to may help them effectively manage their inter-firm relationships. Thus, as suggested by Luo (2007), supply chain partners need justice with regard to procedures, distribution and interaction in order to foster repeated economic exchanges that are gradually embedded in a social-exchange context.

This study, sets out not only to provide new insights concerning justice and SCI practices in supply chain management (SCM) theory, but also has implications for managers to assist them in recognising the synergistic and complementary role between partnering firms in the SCI. It emphasises the principle that managers should promote justice as complementary to SCI practices 
in their firms. The synergistic and complementary view of justice and SCI practice drives relationship performance significantly. Liu et al. (2012) found that, when both parties simultaneously perceive a high level of justice, a profitable and stable relationship becomes possible. This is in line with the bilateral theory that justice and SCI practices complement one another in enabling a firm's performance. Thus, it is recommended that managers examine how supply chain justice and integration practices interact with one another and ensure their complementarities.

\section{Guidelines for empirical research}

\subsection{Research design}

The main purpose of the study is to reveal the relationship between variables that is, supply chain justice dimensions and integration practices as the independent variables and supply chain performance as the dependent variable. For this study, the most appropriate method of analysis is a quantitative research approach, with data being collected through a survey undertaken with a representative sample.

\subsection{Measurement issues}

To empirically test our proposed conceptual framework, interested researchers could develop and refine appropriate measures for the constructs in our model. We present the various constructs used in our model and guidelines for their measurement. The scales for measuring supply chain practices are: information sharing (Cai, Jun \& Yang, 2010; Prajogo \& Olhager, 2012), process integration (Wu, Chiag, Wu, \& Tu, 2004), relationship commitment (Wu et al., 2004), supply chain procedural, distributive (Narasimhan et al., 2013; Griffith et al., 2006), interactional justice (Narasimhan et al., 2013; Luo, 2007) and supply chain performance (SCP) (Cousins \& Menguc, 2006; Panayides \& Venus Lun, 2009). Furthermore, the questionnaire could comprise questions about the demographic profile of the company. All the items can be measured on a seven-point Likert scale ranging from strongly disagree to strongly agree (i.e. $1=$ strongly disagree and $7=$ strongly agree).

We suggest these measures as potential starting points for comprehensive empirical work in this area. Our model contains two sets of variables: one set is associated with the specific dyadic relationship, while the other is not under the control of the dyad. It could be worthwhile to test the dyadic factors of the model using the data collected from a single industry (or closely related industries) and to test the other factors by collecting data from diverse industries.

\subsection{Unit of analysis}

Researchers can consider the dyad as a unit of analysis. Although some independence will be lost between samples, that is, the same organisation could have multiple suppliers and distributors, and vice versa. Moreover, the detailed research could be adapted to address different objectives. As mentioned, some factors are not specific to the dyads but may be common for entire industries; hence to examine the relationships, data must be collected from several industries. We recognise that modifications to the data-collection procedures will be necessary based on the specific nature of the empirical testing, or the nature of the industry (industries) that will be the focus of the analysis, as well as some other data-collection constraints and limits.

\section{Conclusions and future research directions}

In this study, we have proposed a theoretical framework to explain the complementary effects of SCI practices and supply chain justice on firms' SCP. This framework simultaneously incorporates SCI practices and justice that address the SCI relationships. It also lays a solid base for future empirical research on the complementary effects of both important driving forces of SCI. The 
model contributes to the extent of supply chain literature in two ways. First, the model introduces the complementary concept of supply chain justice and SCI practices to the study of SCI and performance. In so doing, the model focuses on the role of supply chain partners in helping to understand the dynamics of SCI. Because, in some ways, perceptions of the complementary role tend to be subjective, an understanding of SCI should include an analysis of the attitude, behaviours and perceptions of those who represent the respective partners in SCI.

Second, the conceptual framework highlights the implications of complementary effects of SCI practices and supply chain justice on performance. It explores the simultaneous consideration of both forces in SCI. This complementary concept has required operationalisation as supply chain partners' perceptions. Our study creates an avenue for future studies. Our work represents an important attempt at the conceptualisation of complementarities of SCI practices and justice dimensions, something that presently has remains as an empirical question. We believe that researchers can develop a normative model for investigation of our conceptual framework. This will allow certain questions to be answered such as: "What is the quantitative impact of combinations of various propositions on firms' SCP?"; "Which combination of SCI practices and justice dimensions will contribute more or less significantly to SCP?"; and "Will these interaction combinations of SCI practices and justice dimensions play a similar or different role in advanced and developing economies?". These and some other important questions must await further conceptual development and empirical research.

\section{Acknowledgements}

The authors wish to thank anonymous referees for their thoughtful consideration and comments. In particular, the authors acknowledge the valuable and constructive suggestions of Professor Leon Oerlemans. This research has been supported by the National Natural Science Foundation (Nos.71432003 and 71271044) of China.

\section{References}

ADAMS, J.S. 1965. Inequity in social exchange. Published in: L. Berkowitz (ed.) Advances in experimental social psychology, 2:267-299. New York: Academic.

ANDERSON, E. \& WEITZ, B. 1992. The use of pledges to build and sustain commitment in distribution channels. Journal of Marketing Research, 29:18-34.

ARIÑO, A. \& RING, P.S. 2010. The role of fairness in alliance formation. Strategic Management Journal, 31(10):1054-1087.

ARMISTEAD, C. \& MAPES, J. 1993. The impact of supply chain integration on operating performance. Logistics Information Management, 6(4):9-14.

ASIAINFO SERVICES. 2004. Gree to set up exclusive stores [Online]. Available at: http://www.highbeam.com/doc/1P1-94661219.html [accessed 2013-01-10].

BARDEN, J.Q., STEENSMA, H.K. \& LYLES, M.A. 2005. The influence of parent control structure on parent conflict in Vietnamese international joint ventures: an organizational justice-based contingency approach. Journal of International Business Studies, 36(2):156-174.

BARUA, A. \& WHINSTON, A.B. 1998. Decision support for managing organizational design dynamics. Decision Support Systems, 22(1):45-58.

BENTON, W.C. \& MALONI, M. 2005. The influence of power driven buyer/seller relationships on supply chain satisfaction. Journal of Operations Management, 23(1):1-22.

BEUGR'E, C.D. 2007. Assessing the organizational justice implications of offshoring. Presentation made at the Academy of Management Annual Meetings, Philadelphia, PA, 3-8.

BEUGRÉ, C.D. \& ACAR, W. 2008. Offshoring and cross-border interorganizational relationships: A justice model. Decision Sciences, 39(3):445-468.

CAI, S., JUN, M. \& YANG, Z. 2010. Implementing supply chain information integration in China: The role of institutional forces and trust. Journal of Operations Management, 28(3):257-268. 
COLQUITT, J.A. 2001. On the dimensionality of organizational justice: A construct validation of a measure. Journal of Applied Psychology, 86(3):386.

COLQUITT, J.A., CONLON, D.E., WESSON, M.J., PORTER, C.O. \& NG, K.Y. 2001. Justice at the millennium: A meta-analytic review of 25 years of organizational justice research. Journal of Applied Psychology, 86(3):425.

CORBETT, C.J., BLACKBURN, J.D. \& VAN WASSENHOVE, L.N. 1999. Partnerships to improve supply chains. Sloan Management Review, 40(4):71-82

COUSINS, P.D. \& MENGUC, B. 2006. The implications of socialization and integration in supply chain management. Journal of Operations Management, 24(5):604-620.

COX, A., SANDERSON, J. \& WATSON, G. 2001. Supply chains and power regimes: Toward an analytic framework for managing extended networks of buyer. The Journal of Supply Chain Management, 37(2):28-35.

CROOK, T.R. \& COMBS, J.G. 2007. Sources and consequences of bargaining power in supply chains. Journal of Operations Management, 25(2):546-555.

CROPANZANA, R., BOWEN, D.E. \& GILLILAND, S.W. 2007. The management of organizational justice. The Academy of Management Perspectives, 21(4):34-48.

DANESE, P., ROMANO, P. \& FORMENTINI, M. 2013. The impact of supply chain integration on responsiveness: The moderating effect of using an international supplier network. Transportation Research Part E. Logistics and Transportation Review, 49(1):125-140.

EDGEWORTH, F.Y. 1881. Mathematical psychics: An essay on the application of mathematics to the moral sciences. London: Kegan Paul.

EISENHARDT, K.M. 1989. Agency theory: An assessment and review. Academy of Management Review, 14(1):57-74.

ENNEN, E. \& RICHTER, A. 2010. The whole is more than the sum of its parts or is it? A review of the empirical literature on complementarities in organizations. Journal of Management, 36(1): 207-233.

FROHLICH, M.T. 2002. e-Integration in the supply chain: Barriers and performance. Decision Sciences, 33(4):537-556.

FROHLICH, M.T. \& WESTBROOK, R. 2001. Arcs of integration: An international study of supply chain strategies. Journal of Operations Management, 19(2):185-200.

GEORGIADES, A. 2008. Wal-Mart Canada, Lego pull apart over price tiff. Wall Street Journal (eastern ed.) 6 February.

GRIFFITH, D.A., HARVEY, M.G. \& LUSCH, R.F. 2006. Social exchange in supply chain relationships: The resulting benefits of procedural and distributive justice. Journal of Operations Management, 24(2):85-98. HALD, K.S. \& ELLEGAARD, C. 2011. Supplier evaluation processes: The shaping and reshaping of supplier performance. International Journal of Operations \& Production Management, 31(8):888-910. HARWIT, E. 1997. Guangzhou Peugeot: Portrait of a commercial divorce. China Business Review, 24(6):10-12.

HENDRIX, W.H., ROBBINS, T., MILLER, J. \& SUMMERS, T.P. 1998. Effects of procedural and distributive justice on factors predictive of turnover. Journal of Social Behavior \& Personality, 13:611-632. HUGHES, A., MCEWAN, C., BEK, D. \& ROSENBERG, Z. 2014. Embedding fair trade in South Africa: Global production networks, national initiatives and localized challenges in the Northern Cape. Competition \& Change, 18(4):291-308.

HULT, G.T.M., KETCHEN, D.J., CAVUSGIL, S.T. \& CALANTONE, R.J. 2006. Knowledge as a strategic resource in supply chains. Journal of Operations Management, 24(5):458-475.

JAROS, S.J., JERMIER, J.M., KOEHLER, J.W. \& SINCICH, T. 1993. Effects of continuance, affective, and moral commitment on the withdrawal process: An evaluation of eight structural equation models. Academy of Management Journal, 36(5):951-995.

JOHNSON, J.P., KORSGAARD, M.A. \& SAPIENZA, H.J. 2002. Perceived fairness, decision control, and commitment in international joint venture management teams. Strategic Management Journal, 23(12): 1141-1160.

JUSKO, J. 2011. How to build a better supplier partnership. Industry Week [online]. Available at: http://www.industryweek.com/global-economy/how-build-better-supplier-partnership [accessed 2013-04-25]. 
KANDA, A. \& DESHMUKH, S.G. 2008. Supply chain coordination: Perspectives, empirical studies and research directions. International Journal of Production Economics, 115(2):316-335.

KETCHENJR, D.J. \& GIUNIPERO, L.C. 2004. The intersection of strategic management and supply chain management. Industrial Marketing Management, 33(1):51-56.

KIM, S.W. 2006. Effects of supply chain management practices, integration and competition capability on performance. Supply Chain Management: An International Journal, 11(3):241-248.

KRAUSE, D.R. 1999. The antecedents of buying firms' efforts to improve suppliers. Journal of Operations Management, 17(2):205-224.

KUMAR, N., SCHEER, L.K. \& STEENKAMP, J.B.E. 1995. The effects of supplier fairness on vulnerable resellers. Journal of Marketing Research, 17:54-65.

LAVIE, D., LECHNER, C. \& SINGH, H. 2007. The performance implications of timing of entry and involvement in multipartner alliances. Academy of Management Journal, 50(3):578-604.

LEE, H.L. 2004. The triple-A supply chain. Harvard Business Review, 82(10):102-113.

LEE, H.L. \& WHANG, S. 2001. E-business and supply chain integration. Stanford, CA: Stanford Global Supply Chain Management Forum. SGSCMF-W2-2001.

LI, G., YANG, H., SUN, L. \& SOHAL, A.S. 2009. The impact of IT implementation on supply chain integration and performance. International Journal of Production Economics, 120(1):125-138.

LIND, E.A. \& TYLER, T.R. 1988. The social psychology of procedural justice. New York: Plenum Press.

LIU, H., LIU, W., KWOK-KEE, W. \& HUA, Z. 2014. The effects of distributive, procedural, and interactional justice on digitally enabled supply chain integration: An upper echelons perspective. PACIS Proceedings.

LIU, Y., HUANG, Y., LUO, Y. \& ZHAO, Y. 2012. How does justice matter in achieving buyer-supplier relationship performance? Journal of Operations Management, 30(5):355-367.

LU, Y. 2006. Toward the micro and macro-level consequences of interactional justice in cross-cultural joint ventures. Human Relations, 59(8):1019-1047.

LUO, Y. 2005. How important are shared perceptions of procedural justice in cooperative alliances? Academy of Management Journal, 48(4):695-709.

LUO, Y. 2007. The independent and interactive roles of procedural, distributive, and interactional justice in strategic alliances. Academy of Management Journal, 50(3):644-664.

MALONI, M. \& BENTON, W.C. 2000. Power influences in the supply chain. Journal of Business Logistics, 21(1):49-74.

MOHR, J. \& SPEKMAN, R. 1994. Characteristics of partnership success: Partnership attributes, communication behavior, and conflict resolution techniques. Strategic Management Journal, 15(2):135-152. MOORE, K.R. 1998. Trust and relationship commitment in logistics alliances: A buyer perspective. Journal of Supply Chain Management, 34(1):24-37.

MORGAN, R.M. \& HUNT, S.D. 1994. The commitment-trust theory of relationship marketing. Journal of Marketing, 58:20-38.

NARASIMHAN, R. \& KIM, S.W. 2002. Effect of supply chain integration on the relationship between diversification and performance: Evidence from Japanese and Korean firms. Journal of Operations Management, 20(3):303-323.

NARASIMHAN, R., NAIR, A., GRIFFITH, D.A., ARLBJØRN, J.S. \& BENDOLY, E. 2009. Lock-in situations in supply chains: A social exchange theoretic study of sourcing arrangements in buyer-supplier relationships. Journal of Operations Management, 27(5):374-389.

NARASIMHAN, R., NARAYANAN, S. \& SRINIVASAN, R. 2013. An Investigation of justice in supply chain relationships and their performance impact. Journal of Operations Management, 31(5):236-247.

NOOTEBOOM, B. 1996. Trust, opportunism and governance: A process and control model. Organization Studies, 17(6):985-1010.

PANAYIDES, P.M. \& VENUS LUN, Y.H. 2009. The impact of trust on innovativeness and supply chain performance. International Journal of Production Economics, 122(1):35-46.

PHILLIPS, J.M., DOUTHITT, E.A. \& HYLAND, M.M. 2001. The role of justice in team member satisfaction with the leader and attachment to the team. Journal of Applied Psychology, 86(2):316. 
PRAJOGO, D. \& OLHAGER, J. 2012. Supply chain integration and performance: The effects of long-term relationships, information technology and sharing, and logistics integration. International Journal of Production Economics, 135(1):514-522.

RANGANATHAN, C., TEO, T.S. \& DHALIWAL, J. 2011. Web-enabled supply chain management: Key antecedents and performance impacts. International Journal of Information Management, 31(6):533-545. RAS, P.J. \& VERMEULEN, W.J. 2009. Sustainable production and the performance of South African entrepreneurs in a global supply chain. The case of South African table grape producers. Sustainable Development, 17(5):325-340.

RING, P.S. \& VAN DE VEN, A.H. 1994. Developmental processes of cooperative interorganizational relationships. Academy of Management Review, 19(1):90-118.

SCHEER, L.K., KUMAR, N. \& STEENKAMP, J.B.E. 2003. Reactions to perceived inequity in US and Dutch interorganizational relationships. Academy of Management Journal, 46(3):303-316.

SCHLOETZER, J.D. 2012. Process integration and information sharing in supply chains. The Accounting Review, 87(3):1005-1032.

SHEU, C., YEN, H.R. \& CHAE, B. 2006. Determinants of supplier-retailer collaboration: Evidence from an international study. International Journal of Operations \& Production Management, 26(1):24-49.

SHOU, Y., FENG, Y., ZHENG, J., WANG, G. \& YEBOAH, N.E. 2013. Power source and its effect on customer-supplier relationships: An empirical study in Yangtze River Delta. International Journal of Production Economics, 146(1):118-128.

TOWILL, D.R. 1997. The seamless supply chain-the predator's strategic advantage. International Journal of Technology Management, 13(1):37-56.

VAN DE VEN, A.H., DELBECQ, A.L. \& KOENIG Jr, R. 1976. Determinants of coordination modes within organizations. American Sociological Review, 41:322-338.

WIENGARTEN, F., HUMPHREYS, P., CAO, G., FYNES, B. \& MCKITTRICK, A. 2010. Collaborative supply chain practices and performance: Exploring the key role of information quality. Supply Chain Management: An International Journal, 15(6):463-473.

WU, W.Y., CHIAG, C.Y., WU, Y.J. \& TU, H.J. 2004. The influencing factors of commitment and business integration on supply chain management. Industrial Management \& Data Systems, 104(4):322-333.

YANG, B. \& BURNS, N. 2003. Implications of postponement for the supply chain. International Journal of Production Research, 41(9):2075-2090.

YEUNG, J.H.Y., SELEN, W., ZHANG, M. \& HUO, B. 2009. The effects of trust and coercive power on supplier integration. International Journal of Production Economics, 120(1):66-78.

ZHAO, X., HUO, B., FLYNN, B.B. \& YEUNG, J.H.Y. 2008. The impact of power and relationship commitment on the integration between manufacturers and customers in a supply chain. Journal of Operations Management, 26(3):368-388.

ZHOU, H. \& BENTON Jr, W.C. 2007. Supply chain practice and information sharing. Journal of Operations Management, 25(6):1348-1365. 